\title{
Metformin inhibits pulmonary artery smooth muscle cell proliferation by upregulating p21 via NONRATT015587.2
}

\author{
ZENGXIAN SUN ${ }^{1,2}$, YUN LIU ${ }^{2}$, RONG HU ${ }^{3}$, TIANYAN WANG ${ }^{2}$, YANLI LI $^{3}$ and NAIFENG LIU ${ }^{1,4}$ \\ ${ }^{1}$ School of Basic Medicine and Clinical Pharmacy, China Pharmaceutical University, \\ Nanjing, Jiangsu 210009; Departments of ${ }^{2}$ Pharmacy and ${ }^{3}$ Respiratory and Critical Care Medicine, \\ The First People's Hospital of Lianyungang, Lianyungang, Jiangsu 222061; ${ }^{4}$ Department of Cardiology, \\ Zhongda Hospital, School of Medicine, Southeast University, Nanjing, Jiangsu 210009, P.R. China
}

Received September 30, 2021; Accepted January 19, 2022

DOI: $10.3892 / \mathrm{ijmm} .2022 .5104$

\begin{abstract}
Pulmonary artery hypertension (PAH) is a complex and progressive disease characterized by pulmonary vascular remodeling. Our previous study confirmed that NONRATT015587.2 could promote the proliferation of PASMCs and pulmonary vascular remodeling. However, the exact mechanism by which NONRATT015587.2 promotes PASMC proliferation is unclear. Bioinformatics analysis revealed that $\mathrm{p} 21$ is located at the downstream target of NONRATT015587.2. NONRATT015587.2 expression and localization were analyzed by PCR and fluorescence in situ hybridization. Proliferation was detected by Cell Counting Kit-8, flow cytometry and western blotting. In the current study, a monocrotaline (MCT)-induced PAH rat model and cultured pulmonary artery smooth muscle cells (PASMCs) were used in vitro to elucidate the exact mechanism of NONRATT015587.2 in pulmonary vascular remodeling, alongside the effect following metformin (MET) treatment on vascular remodeling and smooth muscle cell proliferation. The results demonstrated that NONRATT015587.2 expression was upregulated in the MCT group and reduced in the MET + MCT group. In addition, NONRATT015587.2 could promote the proliferation of PASMCs. The expression levels of p21 were reduced in the MCT group, but increased in the MCT + MET group. Additionally, the expression of NONRATT015587.2 was upregulated in platelet-derived growth factor-BB (PDGF-BB)-induced PASMCs, whereas that of p21 was downregulated. Following MET treatment, the expression of NONRATT015587.2 was downregulated and that of p21 was upregulated, which inhibited the proliferation of PASMCs. After overexpression of NONRATT015587.2
\end{abstract}

Correspondence to: Professor Naifeng Liu, School of Basic Medicine and Clinical Pharmacy, China Pharmaceutical University, 24 Tong Jia Xiang, Nanjing, Jiangsu 210009, P.R. China

E-mail: liunf@seu.edu.cn

Key words: pulmonary artery hypertension, metformin, long non-coding RNA, NONRATT015587.2, p21 in vitro, the proliferation effect of PASMCs was consistent with exogenous PDGF-BB treatment, and MET reversed this effect. NONRATT015587.2 silencing inhibited the proliferation of PASMCs. In addition, p21 silencing reversed the inhibitory effect of NONRATT015587.2 silencing on the proliferation of PASMCs. However, the proliferation of PASMCs was inhibited following MET treatment when NONRATT015587.2 and p21 were silenced at the same time. Thus, NONRATT015587.2 promoted the proliferation of PASMCs by targeting $\mathrm{p} 21$, and MET inhibited the proliferation of PASMCs by upregulating p21 mediated via NONRATT015587.2.

\section{Introduction}

Pulmonary arterial hypertension (PAH) is a complex and progressive disease characterized by persistent pulmonary vasoconstriction, vascular remodeling, in situ thrombosis and perivascular inflammatory infiltration. These pathological features lead to vascular stenosis or occlusion, causing pulmonary blood vessel resistance and a progressive increase in pulmonary artery (PA) pressure, resulting in right heart failure and death (1). Vascular remodeling is a key process in PAH pathogenesis, and abnormal proliferation of vascular smooth muscle cells (VSMCs) plays a key role in this context (2-4). Although great progress has been made in the treatment and understanding of the pathophysiological mechanism underlying PAH, this disease is not preventable and cannot be treated. The overall survival of patients with PAH remains limited (5), and the pathogenesis of this disease has not been fully clarified.

Previous studies have suggested that diabetes (DM) and insulin resistance (IR) are associated with PAH (6-8). DM and IR can specifically affect right ventricular afterload and remodeling in patients with PAH, which have recently been identified as risk factors for PAH deterioration and can reduce survival rate (7). DM and PAH also share common pathological mechanisms, such as chronic inflammation (8). A recent study suggested that these two diseases share a common molecular target, microRNA (miRNA)-7110, which acts as an intermediate molecule linking these two diseases (6).

Metformin (MET) is the most widely used, first-line, oral hypoglycemic agent in clinical practice. Although MET has 
been used clinically for $>50$ years, its mechanism of action in DM has not yet been fully elucidated (9). Epidemiological and clinical studies have revealed that MET reduces the risk of cancer in patients with DM (10-12). It targets the key pathways of cancer cell proliferation and angiogenesis, such as the mTORC1 signaling pathway, and inhibits the proliferation and angiogenesis of cancer cells (10-12). However, the role of MET in PAH pathogenesis remains unclear. Previous studies have confirmed that MET reverses hypoxia-induced and monocrotaline (MCT)-induced PAH in rats and inhibits pulmonary vascular remodeling (13-15).

Long non-coding RNA (lncRNAs) are a class of RNA molecules that regulate numerous biological processes, including genome imprinting, chromosome inactivation, differentiation, carcinogenesis, transcriptional and post-transcriptional regulation $(16,17)$. Abnormal expression of lncRNAs is associated with several human diseases, including various types of cancer, cardiovascular diseases and respiratory diseases (18-20). The mechanism of action of lncRNAs in PAH has attracted increased attention $(21,22)$. For example, metastasis associated lung adenocarcinoma transcript 1 (MALAT1) is highly expressed in the lungs of hypoxic PAH model mice (23), while TCONS_00034812 is expressed at low levels in a rat model of PAH and hypoxic PA smooth muscle cells (PASMCs) (3). Additionally, maternally expressed 3 (MEG3) is expressed at low levels in the lung, PAs and hypoxic human PASMCs of patients with PAH (4). Hoxaas3 is highly expressed in the lung vessels and PASMCs of hypoxic PAH mice (24), while H19 is also highly expressed in the lungs of PAH model rats treated with MCT (25). Moreover, urothelial cancer associated 1 (UCA1) is highly expressed in hypoxic human PASMCs (26).

NONRATT015587.2 is a novel lncRNA with no reported biological function. Our previous study confirmed that NONRATT015587.2 could promote the proliferation of PASMCs via p53 and hypoxia-inducible factor- $1 \alpha$, as well as pulmonary vascular remodeling (22). The exact mechanism through which NONRATT015587.2 promotes the proliferation of PASMCs remains unclear. Previous bioinformatics analysis has revealed that p21 is located at the downstream target of NONRATT015587.2. p21 is regulated by MCT and MET, and its expression is negatively correlated with that of NONRATT015587.2 (22). p21 is a strong cyclin-dependent kinase inhibitor that plays a key role in cell cycle progression and in the control of proliferation $(27,28)$. p21 is a downstream target gene of p53, which is regulated through $\mathrm{p} 53$-dependent and -independent mechanisms $(29,30)$.

The current authors hypothesized that $\mathrm{p} 21$ may be the target gene of NONRATT015587.2. Thus, NONRATT015587.2 may exert its effects on the proliferation of PASMCs by targeting p21, and, in turn, MET may target p21 through NONRATT015587.2, thus blocking the cell cycle at $\mathrm{G}_{0} / \mathrm{G}_{1}$ and inhibiting the proliferation of PASMCs and cell cycle progression. In the present study, NONRATT015587.2 and p21 silencing were performed to explore the pathogenesis of $\mathrm{PAH}$ and the mechanism of action of MET in the prevention and treatment of this disease, in the hope that the findings may highlight new strategies for the prevention and treatment of PAH.

\section{Materials and methods}

Animal model. All animal experiments were approved by the Animal Care and Use Institutional Committee of China Pharmaceutical University prior to the initiation of the present study (approval no. YKD-20180207001). A total of 30 female Sprague-Dawley rats (age, 8 weeks; weight range, 200-220 g) were purchased from the Experimental Animal Center of Nantong University (Nantong, China). The rats were housed in groups of five at $23^{\circ} \mathrm{C}$ under a $12 \mathrm{~h}$ light/dark cycle and a relative humidity of $45 \%$, with free access to food and water. The rats were randomly divided into three groups as follows: i) The control group, which were administered normal saline; ii) the MCT group, which were administered a single subcutaneous injection of $60 \mathrm{mg} / \mathrm{kg}$ MCT (31); and iii) the MCT + MET, which were administered a single subcutaneous injection of $60 \mathrm{mg} / \mathrm{kg}$ MCT and MET (100 mg/kg/day via intragastrical injection; Sigma-Aldrich; Merck KGaA). An injection of sodium chloride $0.9 \%(5 \mathrm{ml} / \mathrm{kg}$ ) was given to control and MCT groups every day for a total of 30 days by intragastric administration. MET was administered intragastrically at a dose of $100 \mathrm{mg} / \mathrm{kg} /$ day every day for 30 days, starting on the day of MCT injection (day 0). After the model was successfully constructed, the rats were anesthetized using 3\% sodium pentobarbital $(45 \mathrm{mg} / \mathrm{kg}$ ) injected into the abdominal cavity. After anesthesia, the chest cavity was opened along the ribs on both sides with tissue scissors to expose the heart and lungs. Surgical scissors were used to remove the heart and lung for subsequent experiments.

Hemodynamic experiments. Right ventricular systolic pressure (RVSP) and right ventricle/left ventricle + septum $(\mathrm{RV} / \mathrm{LV}+\mathrm{S})$ were analyzed as previously described (22). The lung tissue samples were then fixed with $4 \%$ paraformaldehyde at $4^{\circ} \mathrm{C}$ for $24 \mathrm{~h}$ and embedded in paraffin for subsequent immunohistochemistry experiments.

Immunohistochemistry. Tissue samples were cut into $4-\mu \mathrm{m}$ sections for immunohistochemistry. The slices were baked in an oven at $60^{\circ} \mathrm{C}$ for $2 \mathrm{~h}$. Dewaxing, rehydration and antigen retrieval were then performed. Slices were placed in $0.01 \mathrm{M}$ sodium citrate buffer solution ( $\mathrm{pH}$ 6.0) and heated in the microwave for $4 \mathrm{~min}$ until boiling. Sections were then heated four times for 6 min each, replenishing the liquid at each interval to prevent the slices from drying out. Lung tissue sections were subsequently incubated with $5 \%$ goat serum for $30 \mathrm{~min}$ at room temperature. Platelet-derived growth factor subunit B (PDGFB; cat. no. AF0240; 1:200; Affinity Biosciences) and p21 (cat. no. AF6290; 1:200; Affinity Biosciences) primary antibodies were then added at $4^{\circ} \mathrm{C}$ for $12 \mathrm{~h}$. After overnight incubation, the sections were washed three times with PBS and then exposed to HRP-conjugated Affinipure goat anti-rabbit IgG(H+L) secondary antibodies (cat. no. SA00001-2; 1:200; ProteinTech Group, Inc.) for $60 \mathrm{~min}$ at room temperature. Positivity for PDGFB and p21 was reflected by brown staining. An IX73 light microscope (magnification, x10; Olympus Corporation) was used for the acquisition of light images.

Rat PASMC culture. Rat PASMCs were isolated from the lung tissue of healthy Sprague-Dawley rats. The lung tissue was 
placed in sterile PBS to wash away blood, then placed under a microscope in order to strip the PA vessels. Microscissors and forceps were used to remove the adventitia and intima of the PAs. The PAs were then cut into 1-2 mm pieces with microscissors and digested with a mixture containing $2 \mathrm{mg} / \mathrm{ml}$ collagenase, $0.5 \mathrm{mg} / \mathrm{ml}$ elastase and $1.5 \mathrm{mg} / \mathrm{ml} \mathrm{BSA} \mathrm{(Nanjing} \mathrm{KeyGen}$ Biotech Co., Ltd.) for 1-2 h until the tissue mass became a cell mass. DMEM (Hyclone; Cytiva) containing 10\% fetal bovine serum (FBS; Gibco; Thermo Fisher Scientific, Inc.) was added to the cell pellets to stop the digestion by pipetting, after which the supernatant was removed by centrifugation at $2,000 \mathrm{x} \mathrm{g}$ at room temperature for $5 \mathrm{~min}$. PASMCs were resuspended in DMEM containing $10 \% \mathrm{FBS}$ in a cell culture flask and maintained in an incubator at $37^{\circ} \mathrm{C}$ with $5 \% \mathrm{CO}_{2}$. The purity of PASMCs was determined using a monoclonal antibody specific for $\alpha$-smooth muscle actin (cat. no. AH11074812; 1:200; BIOSS) at $4^{\circ} \mathrm{C}$ for $12 \mathrm{~h}$. Platelet-derived growth factor-BB (PDGF-BB) (cat. no. 100-14B; PeproTech, Inc.) was used to stimulate cell proliferation. Cells from passage 2-5 were used for subsequent experiments.

Reverse transcription-quantitative PCR (RT-qPCR) analysis. RT-qPCR was performed as previously described (22). Total RNA was extracted from PAs and PASMCs using Trizol ${ }^{\circledR}$ reagent (Invitrogen; Thermo Fisher Scientific, Inc.). The yield of RNA was assessed using a NanoDrop 2000 spectrophotometer (Thermo Fisher Scientific, Inc.), after which the integrity was evaluated using $1 \%$ agarose gel electrophoresis stained with ethidium bromide. RT was performed using a miScript ${ }^{\circledR}$ II RT kit (Qiagen, Inc.; cat. no. 218160). Reactions were analyzed in GeneAmp ${ }^{\circledR}$ PCR System 9700 (Applied Biosystems; Thermo Fisher Scientific, Inc.) under the following temperature protocol: $25^{\circ} \mathrm{C}$ for $10 \mathrm{~min}, 50^{\circ} \mathrm{C}$ for $30 \mathrm{~min}$ and at $85^{\circ} \mathrm{C}$ for $5 \mathrm{~min}$. The $10 \mu \mathrm{l}$ RT reaction mix was then diluted $10 \mathrm{x}$ in nuclease-free water and held at $-20^{\circ} \mathrm{C}$. qPCR was performed using a LightCycler ${ }^{\circledR} 480$ II Real-time PCR Instrument (Roche Diagnostics) with $10 \mu 1 \mathrm{PCR}$ reaction mixture that included $1 \mu$ cDNA, $5 \mu 1$ 2x QuantiFast ${ }^{\circledR}$ SYBR $^{\circledR}$ Green PCR Master Mix (Qiagen $\mathrm{GmbH}$ ), $0.2 \mu \mathrm{l}$ forward primer, $0.2 \mu \mathrm{l}$ reverse primer and $3.6 \mu \mathrm{l}$ nuclease-free water. Reactions were incubated in 96-well plates (Roche Diagnostics) under the following thermocycling conditions: $95^{\circ} \mathrm{C}$ for $5 \mathrm{~min}$, followed by 40 cycles of $95^{\circ} \mathrm{C}$ for $10 \mathrm{sec}$ and $60^{\circ} \mathrm{C}$ for $30 \mathrm{sec}$. Each sample was run in triplicate for analysis. At the end of PCR cycling, melting curve analysis was performed to validate the specific generation of the expected PCR product. The primer sequences were designed in the laboratory and were synthesized by Generay Biotech (Generay Biotech Co., Ltd.) based on the mRNA sequences obtained from the NCBI database. The sequences of the primers are presented in Table I. The expression levels of NONRATT015587.2 were normalized to those of $\beta$-actin and were calculated using the $2^{-\Delta \Delta \mathrm{Cq}}$ method (32).

Western blotting. RIPA protein lysis buffer (cat. no. KGP702-100; Nanjing KeyGen Biotech Co., Ltd.) was added to PA homogenate or PASMCs to extract protein. The protein concentration was quantified using bicinchoninic acid protein concentration kit (Nanjing KeyGen Biotech Co., Ltd.). Samples containing $20 \mu \mathrm{g}$ total protein were added to $5 \mathrm{X}$ loading buffer for denaturation at $95^{\circ} \mathrm{C}$, then resolved using
Table I. Specific primer sequences used in PCR.

\begin{tabular}{lc} 
Oligonucleotides & Sequence (5'-3') \\
\hline $\begin{array}{l}\text { NONRATT015587.2 } \\
\text { Forward }\end{array}$ & \\
Reverse & ACATGACCTCTAAAGATTCTGC \\
$\beta$-actin & GACCATTCCTACATCTCCCA \\
Forward & \\
Reverse & CCACCATGTACCCAGGCATT \\
& CGGACTCATCGTACTCCTGC
\end{tabular}

$10 \%$ SDS-PAGE, transferred to a nitrocellulose membrane, blocked with $5 \%$ skimmed milk for $1 \mathrm{~h}$ at room temperature and incubated with primary antibodies at $4^{\circ} \mathrm{C}$ overnight. The primary antibodies used were as follows: p21 (cat. no. AF6290; 1:1,000; Affinity Biosciences), proliferating cell nuclear antigen (PCNA; cat. no. 10205-2-AP; 1:5,000; ProteinTech Group,Inc.), cyclin A (cat.no. 13295-1-AP; 1:1,000; ProteinTech Group,Inc.), cyclin E (cat. no. 11554-1-AP; 1:2,000; ProteinTech Group,Inc.), GAPDH (cat. no. 60004-1-1 g; 1:5,000; ProteinTech Group, Inc.) and $\beta$-actin (cat. no. 60008-1-1 g; 1:10,000; ProteinTech Group, Inc.). The membranes were then incubated with HRP-conjugated anti-mouse (cat. no. SA00001-1; 1:20,000; ProteinTech Group, Inc.) or anti-rabbit IgG (cat. no. SA00001-2; 1:20,000; ProteinTech Group, Inc.) secondary antibodies for $1 \mathrm{~h}$ at room temperature. The membranes were washed with TBS $+0.1 \%$ Tween for $40 \mathrm{~min}$ at room temperature, after which electrochemiluminescence (Nanjing KeyGen Biotech Co., Ltd.) solution was added for $5 \mathrm{~min}$. The bands were analyzed using a VersaDoc ${ }^{\mathrm{TM}}$ MP 4000 instrument (Bio-Rad Laboratories, Inc.) with PDQuest Advanced 2D analysis software (version 8.0; Bio-Rad Laboratories, Inc.).

Transfection. The sequences of small interfering RNA (siRNA) targeting NONRATT015587.2 and the non-targeted negative control (NC) were synthesized by Shanghai GenePharma Co., Ltd. The sequences were as follows: si-NONRATT015587.2 sense, 5'-GCCUGGUUCAUUGUUGGUUTT-3' and antisense, 5'-AACCAACAAUGAACCAGGCTT-3'; si-p21 (33) sense, 5'-GGAACAAGGAGUCAGACAUTT-3' and antisense, 5'-AUGUCUGACUCCUUGUUCCTT-3'; NC sense, 5'-UUC UCCGAACGUGUCACGUTT-3' and antisense, 5'-ACG UGACACGUUCGGAGAATT-3'. The NONRATT015587.2 overexpression plasmid (pcDNA-NONRATT015587.2) was constructed by Shanghai GenePharma Co., Ltd. After_6 h of transfection, subsequent experiments were performed. A total of $2 \mu \mathrm{g}$ siRNA and $10 \mu \mathrm{l}$ Lipofectamine ${ }^{\circledR} 2000$ transfection reagent (Invitrogen; Thermo Fisher Scientific, Inc.) were diluted in serum-free Opti-MEM-1 (Gibco; Thermo Fisher Scientific, Inc.) medium and mixed together. The mixture (siRNA/Transfection Reagent) was then incubated at room temperature for $20 \mathrm{~min}$ and added directly onto cells. After $6 \mathrm{~h}$ of exposure to siRNA, the transfection reagents were removed and PASMCs were cultured in DMEM containing 5\% FBS for a further $24 \mathrm{~h}$ in an incubator at $37^{\circ} \mathrm{C}$ with $5 \% \mathrm{CO}_{2}$. Cells treated with transfection reagent alone (mock) and untreated PASMCs (blank) from the same isolation served as additional negative controls. 
Cell Counting Kit-8 (CCK-8) analysis. PASMCs were digested with trypsin and collected by centrifugation at $2,000 \mathrm{x} \mathrm{g}$ at room temperature for $5 \mathrm{~min}$ to prepare a cell suspension, then seeded in 96-well plates at a density of $1 \times 10^{4}$ cells/well. PASMCs were treated according to different experimental groups. After incubation at $37^{\circ} \mathrm{C}$ in $5 \% \mathrm{CO}_{2}$ for $24 \mathrm{~h}, 20 \mu \mathrm{lCCK}-8$ was added to the cells for $4 \mathrm{~h}$ at $37^{\circ} \mathrm{C}$. Absorbance was analyzed using a Synergic2 multiplate reader (Synergy H1; BioTek) at $450 \mathrm{~nm}$.

Cell cycle analysis. Propidium iodide single staining was used to analyze the cell cycle. PASMCs were digested with trypsin and centrifuged at 2,000 $\mathrm{x} g$ at room temperature for $5 \mathrm{~min}$. The cells were washed three times by centrifugation at $2,000 \times \mathrm{g}$ at room temperature for $5 \mathrm{~min}$ with PBS, then fixed with $70 \%$ ethanol for $24 \mathrm{~h}$ at $4^{\circ} \mathrm{C}$. After washing with ethanol, the cells were incubated with $200 \mu \mathrm{l}$ PBS. Solution A was added according to the instructions of the flow cytometry cycle detection kit (BD Biosciences), and the cells were then incubated for $10 \mathrm{~min}$ at room temperature. Solution B was then added. Finally, solution $\mathrm{C}$ was added to the cells, which were then incubated for $10 \mathrm{~min}$ in the dark at room temperature. DNA fluorescence measurements were analyzed using a flow cytometer (FACSCanto II; BD Biosciences). The results were analyzed using the ModFit software (version 4.1; Verity Software House, Inc.).

PASMC RNA fluorescence in situ hybridization (FISH). Fluorescence-conjugated 1ncRNA NONRATT015587.2 probes were synthesized by Guangzhou RiboBio Co., Ltd. and used for RNA FISH. Hybridization was performed using an RNA FISH kit (Guangzhou RiboBio Co., Ltd.) according to the manufacturer's instructions. The FISH sections were then incubated with DAPI for $5 \mathrm{~min}$ at room temperature. An IX73 fluorescence microscope (magnification, x10; Olympus Corporation) was used for the acquisition of fluorescent images.

Statistical analysis. Data are presented as the mean \pm SD of at least three independent experiments and were analyzed using one-way ANOVA. Tukey's post-hoc test was used for pairwise comparisons. Statistical analysis was carried out using data analysis tool (PAST v2.17) software (WinAll Application Platform). $\mathrm{P}<0.05$ was considered to indicate a statistically significant difference.

\section{Results}

NONRATT015587.2 and p21 expression and intracellular localization of NONRATT015587.2 in PAH model rats. To determine whether MET reversed MCT-induced PAH, in vivo $\mathrm{RVSP}$ and $\mathrm{RV} /(\mathrm{LV}+\mathrm{S})$ were calculated. The results demonstrated that MET attenuated the increase in RVSP and $\mathrm{RV} /(\mathrm{LV}+\mathrm{S}$ ) induced by MCT (Fig. 1A and B). Our previous study suggested that the expression of IncRNA NONRATT015587.2 was significantly upregulated in the MCT group and significantly downregulated following MET intervention. The expression levels of the p21 gene were negatively correlated with those of NONRATT015587.2 (MCT group, $\mathrm{r}=-0.894$ and $\mathrm{P}=0.016$; $\mathrm{MCT}+\mathrm{MET}$ group, $\mathrm{r}=-0.957$ and $\mathrm{P}=0.0028)(22)$. In the present study, the expression levels of NONRATT015587.2 and $\mathrm{p} 21$ protein were analyzed in the PAs of each group of rats. The expression levels of NONRATT015587.2 were significantly upregulated in the MCT group compared with those of the control group; however, NONRATT015587.2 was significantly downregulated following MET treatment (Fig. 1C). Moreover, p21 protein expression levels were significantly downregulated in the MCT group and upregulated after MET treatment (Fig. 1D and E). These results are consistent with those included in our previous bioinformatics analysis (22). In addition, PDGFB was highly expressed in the MCT group, but markedly downregulated following treatment with MET (Fig. 1D).

In order to further analyze the relationship between NONRATT015587.2 and 21,FISHfluorescent probes were used to analyze the subcellular localization of NONRATT015587.2. The results indicated that NONRATT015587.2 was located in the nucleus (Fig. 1F).

PDGF-BB promotes the proliferation of PASMCs. A concentration gradient of PDGF-BB was used to stimulate the cell viability of PASMCs in vitro in order to observe its effect on these cells. The results suggested that PASMCs cell viability gradually increased (Fig. 2A) and that the expression of NONRATT015587.2 significantly increased with increasing PDGF-BB concentrations (Fig. 2B), reaching a maximum at a concentration of $30 \mathrm{ng} / \mathrm{ml}$. However, p21 exhibited the opposite trend, and its protein expression levels decreased with increasing PDGF-BB concentrations, reaching its lowest at $30 \mathrm{ng} / \mathrm{ml}$ (Fig. 2C). Moreover, the protein expression levels of cyclin E, cyclin A and PCNA increased in a dose dependent manner (Fig. 2D).

The results of flow cytometry indicated that PDGF-BB treatment resulted in a gradual decrease in the proportion of cells in the $G_{0} / G_{1}$ phase. By contrast, the proportion of cells in the $\mathrm{S}$ phase gradually increased, indicating that transition through the $G_{0} / G_{1}$ cell cycle phase was accelerated, indicative of enhanced proliferation and replication (Fig. 2E). These observations suggested that PDGF-BB stimulation promoted the proliferation of PASMCs in a concentration-dependent manner, reaching a maximum at a concentration of $30 \mathrm{ng} / \mathrm{ml}$. Based on the aforementioned results, the concentration of $30 \mathrm{ng} / \mathrm{ml}$ was used in subsequent experiments.

MET inhibits PDGF in proliferating PASMCs and inhibits its effect on the expression of NONRATT015587.2 and p21. Our previous study suggested that MET treatment could reverse MCT-induced PAH and vascular remodeling (22). In addition, Song et al (34) revealed that MET could reduce PDGF-induced PASMC proliferation. In the present study, the effect of MET on the proliferation of PASMCs was examined, in order to select the appropriate concentration for MET. PDGF-BB-induced proliferation of PASMCs was reversed by MET and was gradually reduced with increasing MET concentrations, reaching its lowest at $20 \mathrm{mM}$ (Fig. 3A). A number of previous reports have indicated that MET inhibits tumor cell proliferation. The pathological features of pulmonary hypertension are very similar to tumors, a common feature of which is the abnormal proliferation of cells. Therefore, when selecting the appropriate concentration of MET in vitro, previously reported 
A
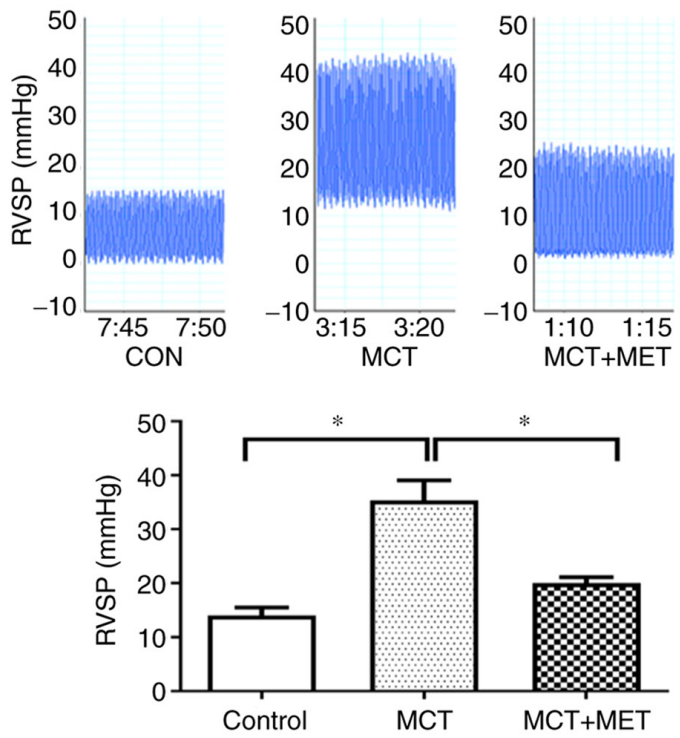

C

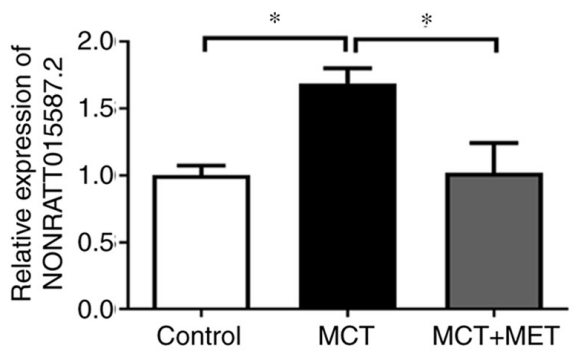

$\mathrm{E}$
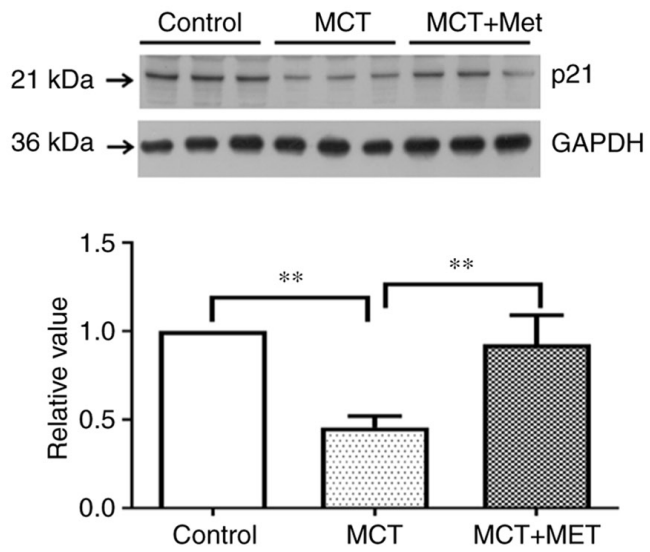
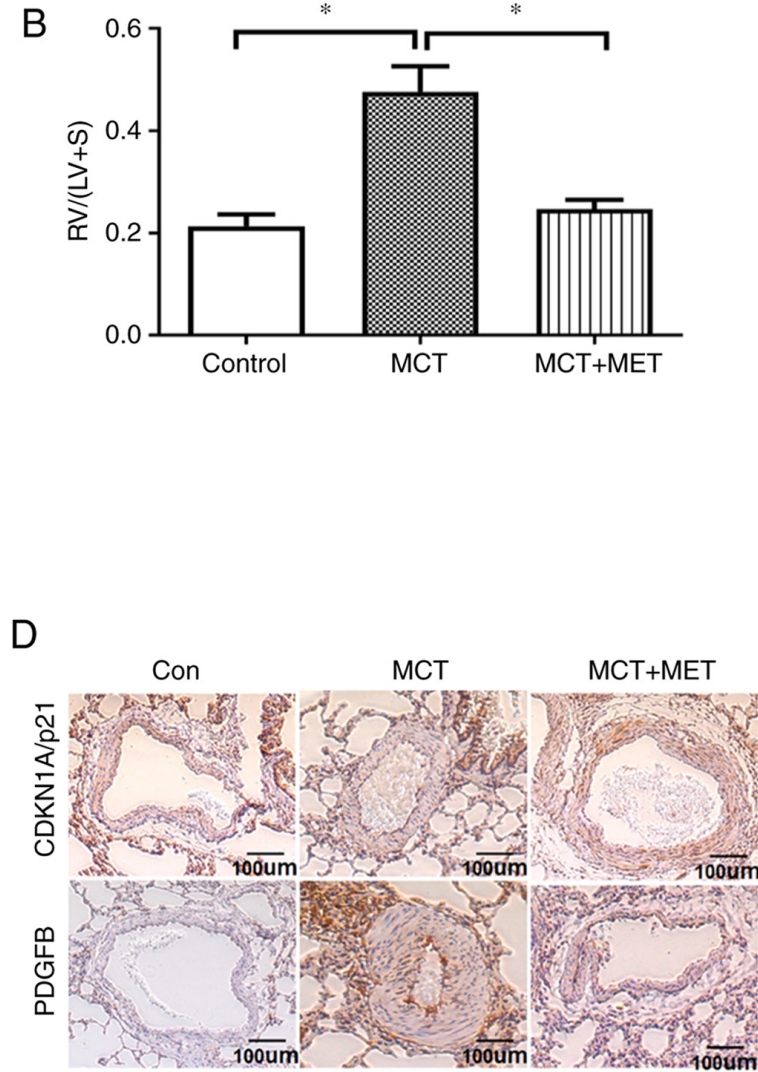

$\mathrm{F}$

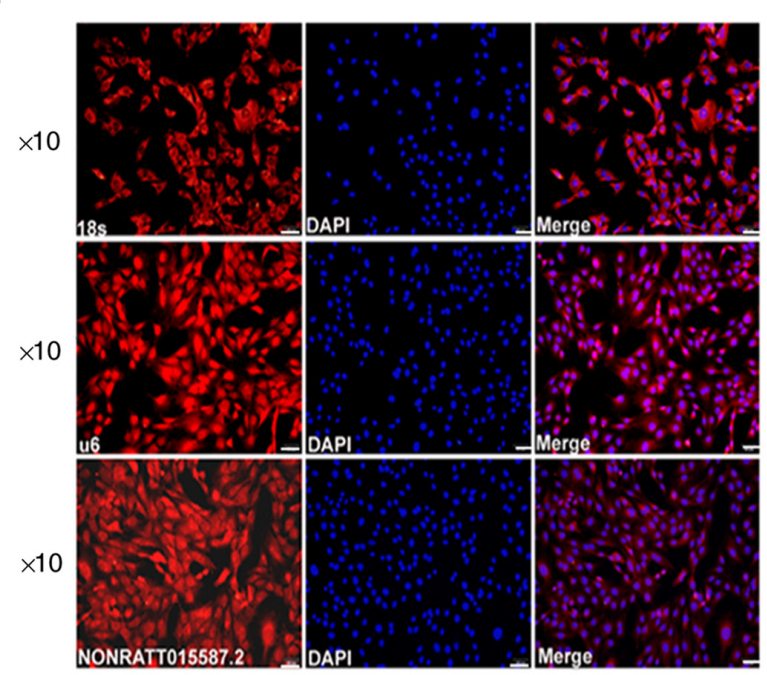

Figure 1. Expression of NONRATT015587.2 and p21 in MCT-induced pulmonary hypertension rats. (A) Assessment of RVSP in MCT-induced PAH rats, controls and following MCT+MET treatment. (B) Changes in the RV/(LV+S) ratio. (C) NONRATT015587.2 gene expression was calculated in each group. (D) The expression of CDKN1A/p21 and PDGFB in pulmonary artery tissue was analyzed by immunohistochemistry staining (scale bars, $100 \mu$ m). (E) p21 protein expression was determined via western blotting and subsequently quantified. (F) Fluorescence in situ hybridization was performed to analyze the subcellular location of NONRATT015587.2. In this experiment, 18s was used as the cytoplasmic reference gene and u6 was used as the nuclear reference gene. DAPI was used for nuclear staining (scale bars, $50 \mu \mathrm{m})$. Data represent mean \pm standard deviation $(\mathrm{SD})$. ${ }^{*} \mathrm{P}<0.05$ and ${ }^{* *} \mathrm{P}<0.01$ as indicated $(\mathrm{n}=\geq 3)$. Con, control; MCT, monocrotaline; MET, metformin; PDGFB, platelet-derived growth factor subunit B; RV/(LV+S), right ventricle/left ventricle plus septum; RVSP, right ventricular systolic pressure.

literature (35-38) and our previous published article (39) was referred to. Following MET treatment, the expression of NONRATT015587.2 was significantly downregulated (Fig. 3B), while that of the p21 protein was significantly 
A

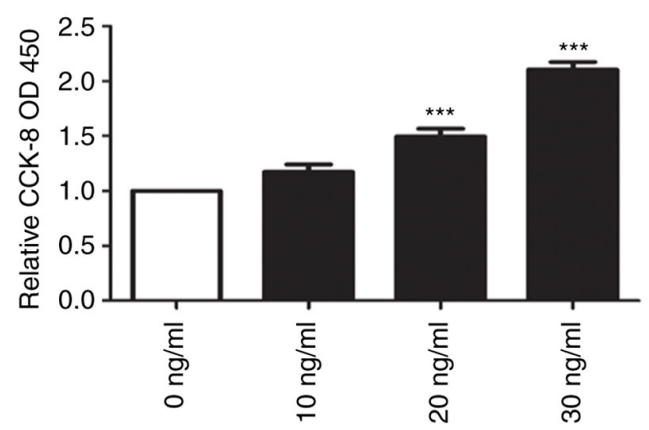

C
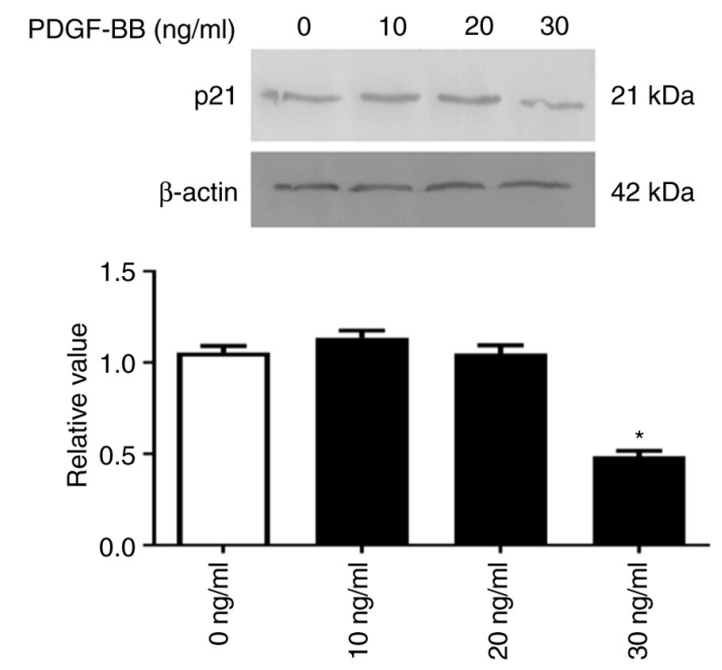

E
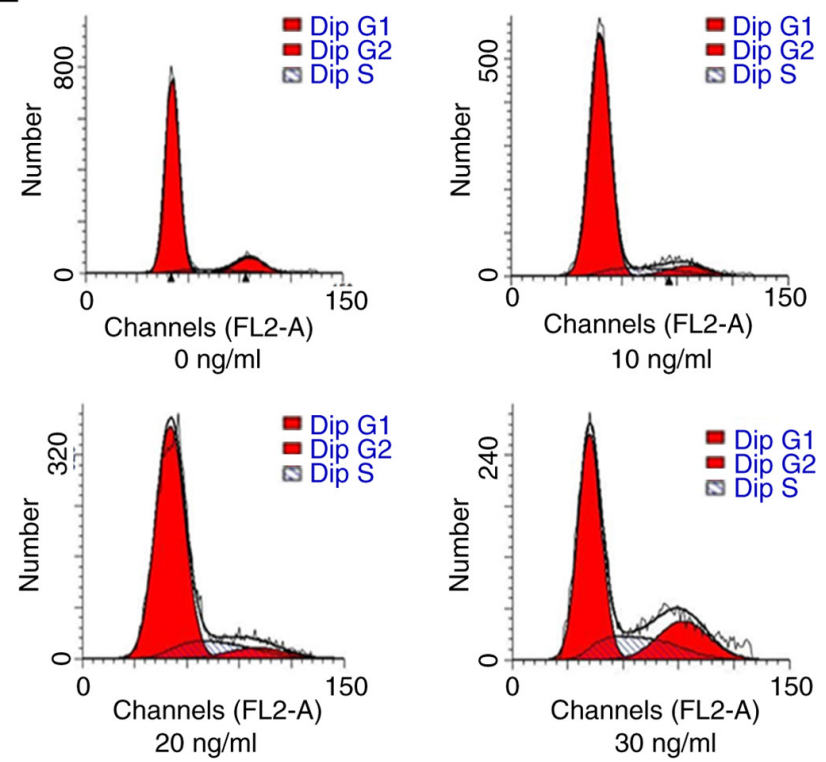

B

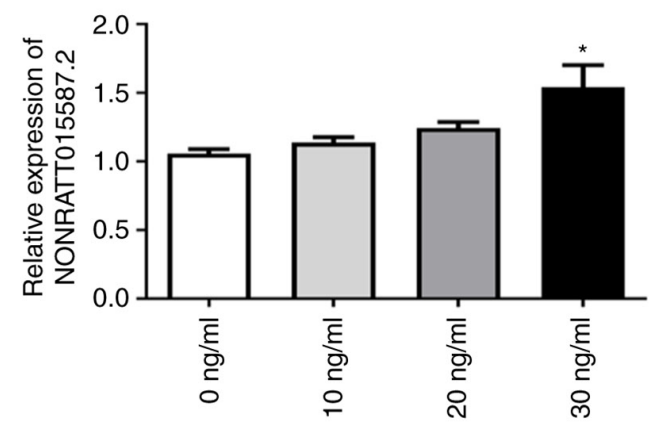

$\mathrm{D}$
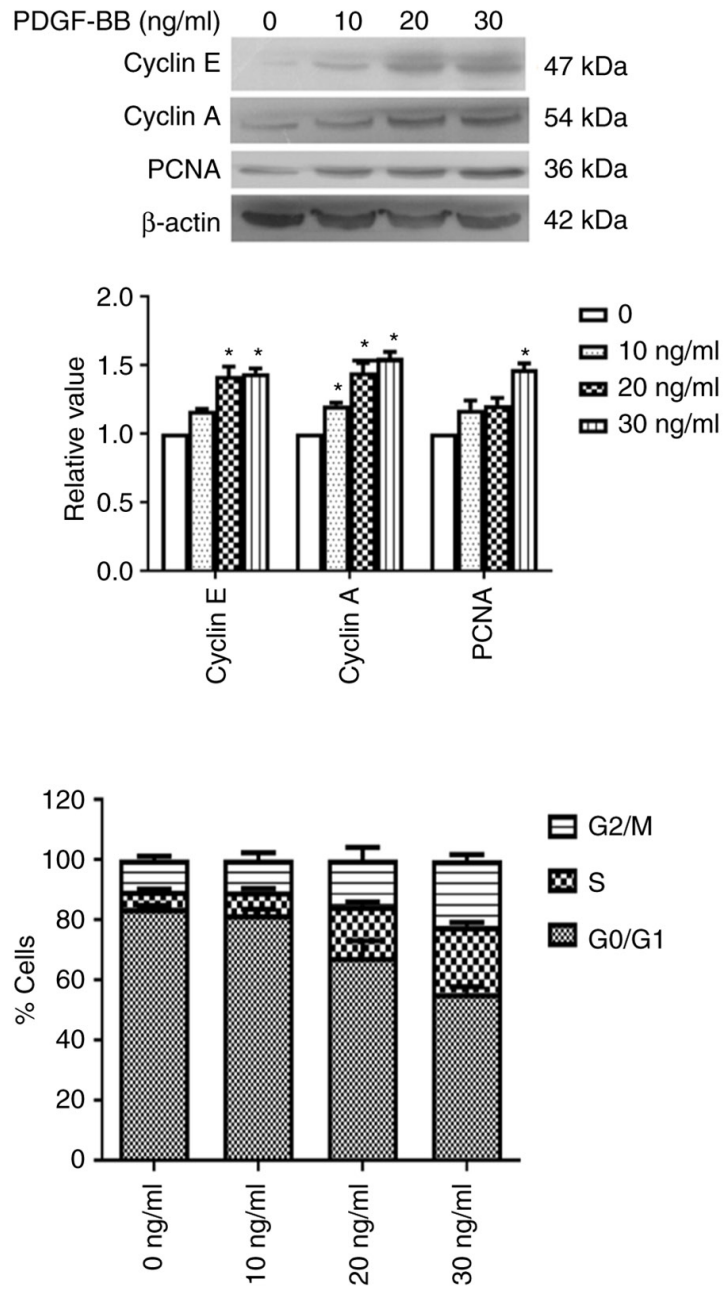

Figure 2. Effect of PDGF-BB on PASMCs proliferation, NONRATT015587.2 and p21 expression. (A) Cell proliferation was detected by performing a CCK-8 assay with different PDGF-BB concentrations. (B) Expression of NONRATT015587.2 at different PDGF-BB concentrations. (C) Effect of different PDGF-BB concentrations on the expression of $\mathrm{p} 21$ protein. (D) Effect of different concentrations of PDGF-BB on the expression of Cyclin E, Cyclin A, PCNA protein in PASMCs. (E) Effect of different concentrations of PDGF-BB on the PASMC cycle. ${ }^{*} \mathrm{P}<0.05$ and ${ }^{* * *} \mathrm{P}<0.001 \mathrm{vs}$. the $0 \mathrm{ng} / \mathrm{ml}$ group ( $\mathrm{n}=\geq 3$ ). CCK-8, Cell Counting Kit-8; OD, optical density; PASMCs, pulmonary artery smooth muscle cells; PCNA, proliferating cell nuclear antigen; PDGF-BB, platelet-derived growth factor-BB.

upregulated (Fig. 3C). In addition, the observed effects on cell proliferation (Fig. 3D) and cell cycle progression (Fig. 3E), as well as cyclin E, cyclin A and PCNA protein expression (Fig. 3F), were reversed by MET.
NONRATT015587.2 promotes the proliferation of PASMCs. In our previous study, PASMC proliferation was examined following overexpression of NONRATT015587.2 (22). In the present study, the effect of NONRATT015587.2 overexpression 
A
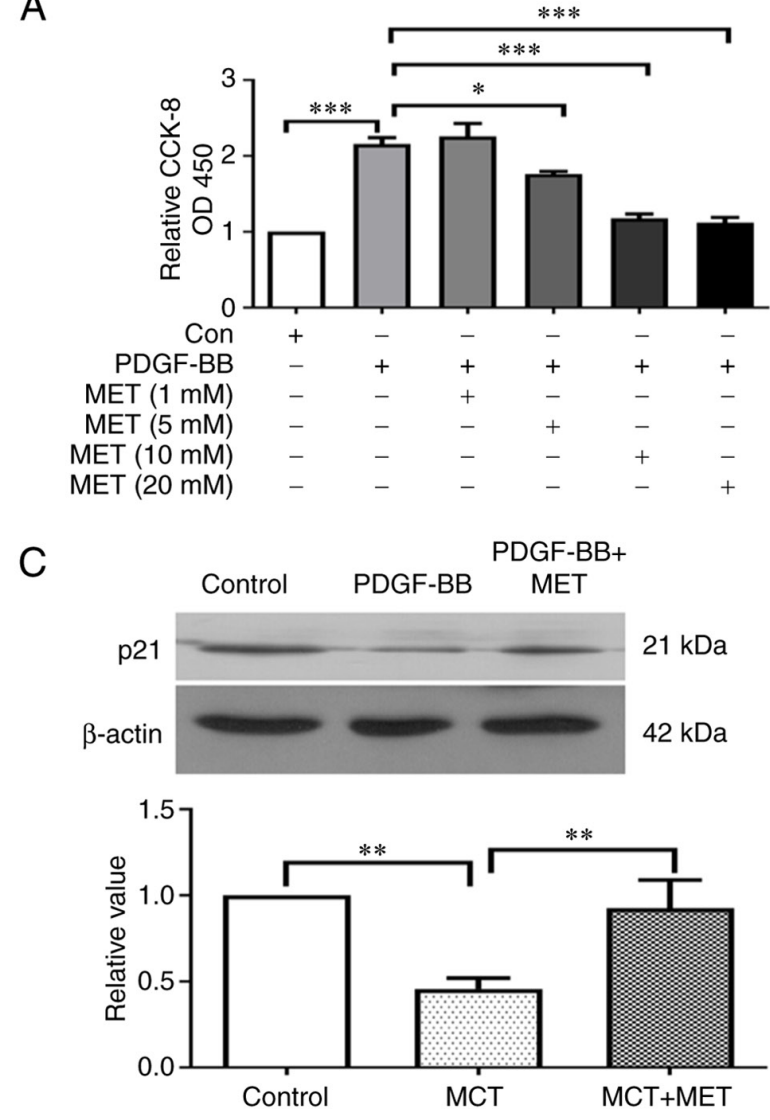

B

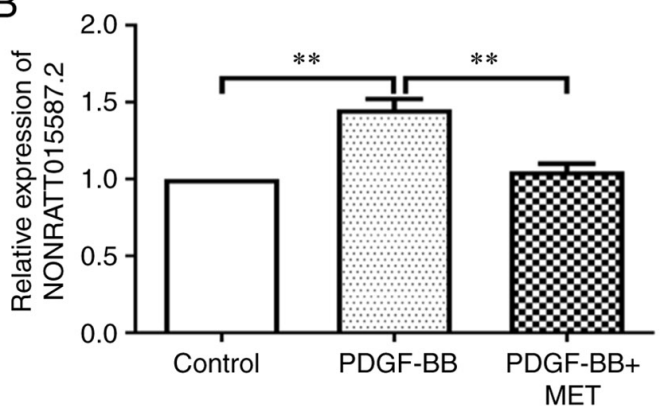

D

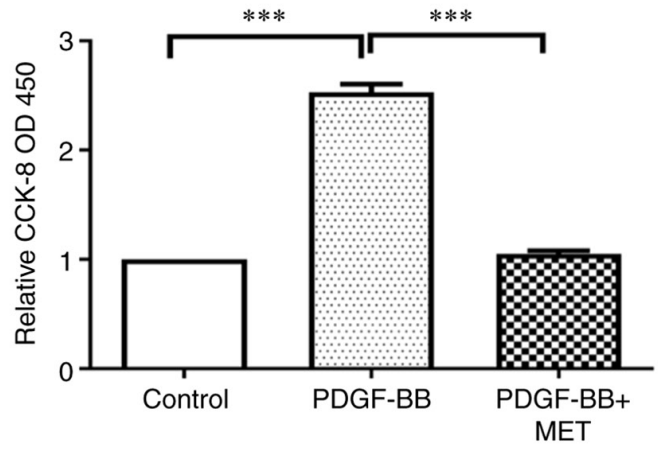

F
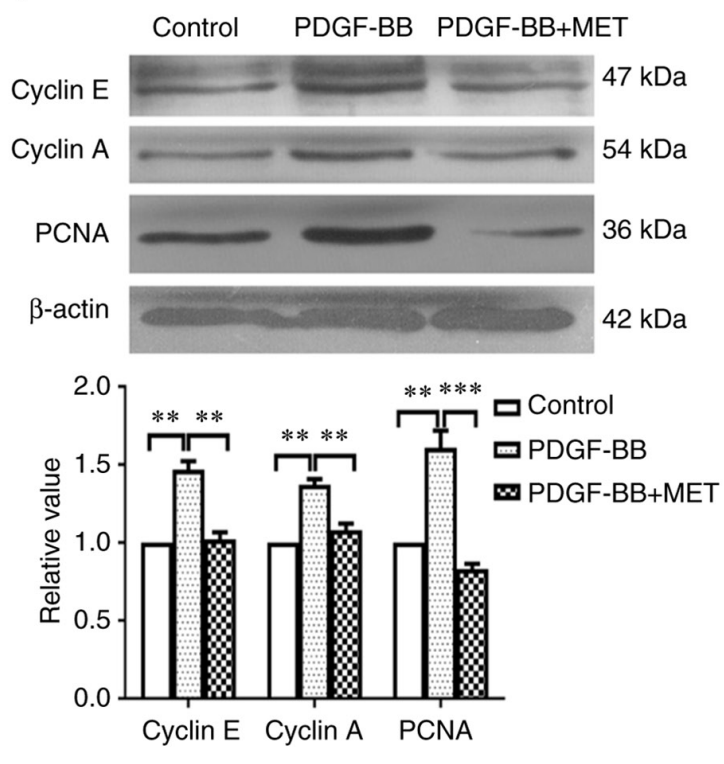

Figure 3. MET reverses the biological effects of PDGF-BB on PASMCs. (A) A CCK-8 assay was used to analyze the inhibitory effect of different concentrations of metformin on PDGF-BB-induced PASMC proliferation. (B) RNA expression levels of NONRATT015587.2. (C) Protein expression level of p21. (D) CCK-8 was performed to analyze the proliferation of PASMCs after PDGF-BB and MET treatment. (E) The cell cycles was analyzed in PASMCs after PDGF-BB and MET treatment. (F) The protein expression of PCNA, Cyclin A and Cyclin E was determined in PASMCs under different conditions. ${ }^{*} \mathrm{P}<0.05$, ${ }^{* *} \mathrm{P}<0.01$ and ${ }^{* * *} \mathrm{P}<0.001$ ( $\mathrm{n}=\geq 3$ ). CCK-8, Cell Counting Kit-8; Con, control; MET, metformin; OD, optical density; PASMCs, pulmonary artery smooth muscle cells; PCNA, proliferating cell nuclear antigen; PDGF-BB, platelet-derived growth factor-BB.

on PASMC proliferation and the possible underlying mechanism were investigated (Fig. 4). Flow cytometry results revealed that the proportion of cells in the $S$ phase following NONRATT015587.2 overexpression was increased; however, this was reduced to the levels of the pcDNA group following MET treatment (Fig. 4A). Moreover, PASMC proliferation, as well as cyclin E, cyclin A and PCNA protein expression levels, were significantly increased following NONRATT015587.2 

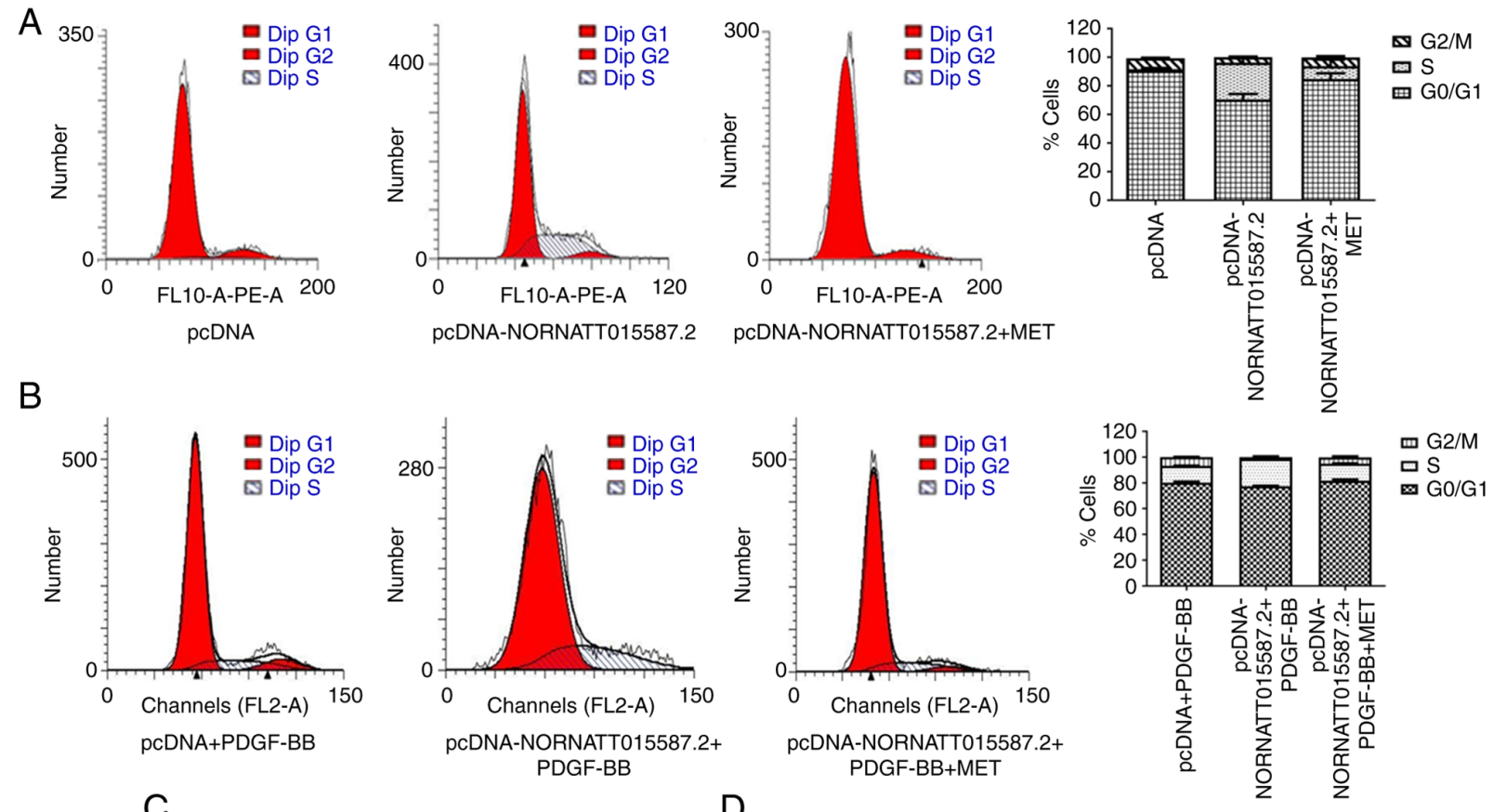

C

$\mathrm{D}$
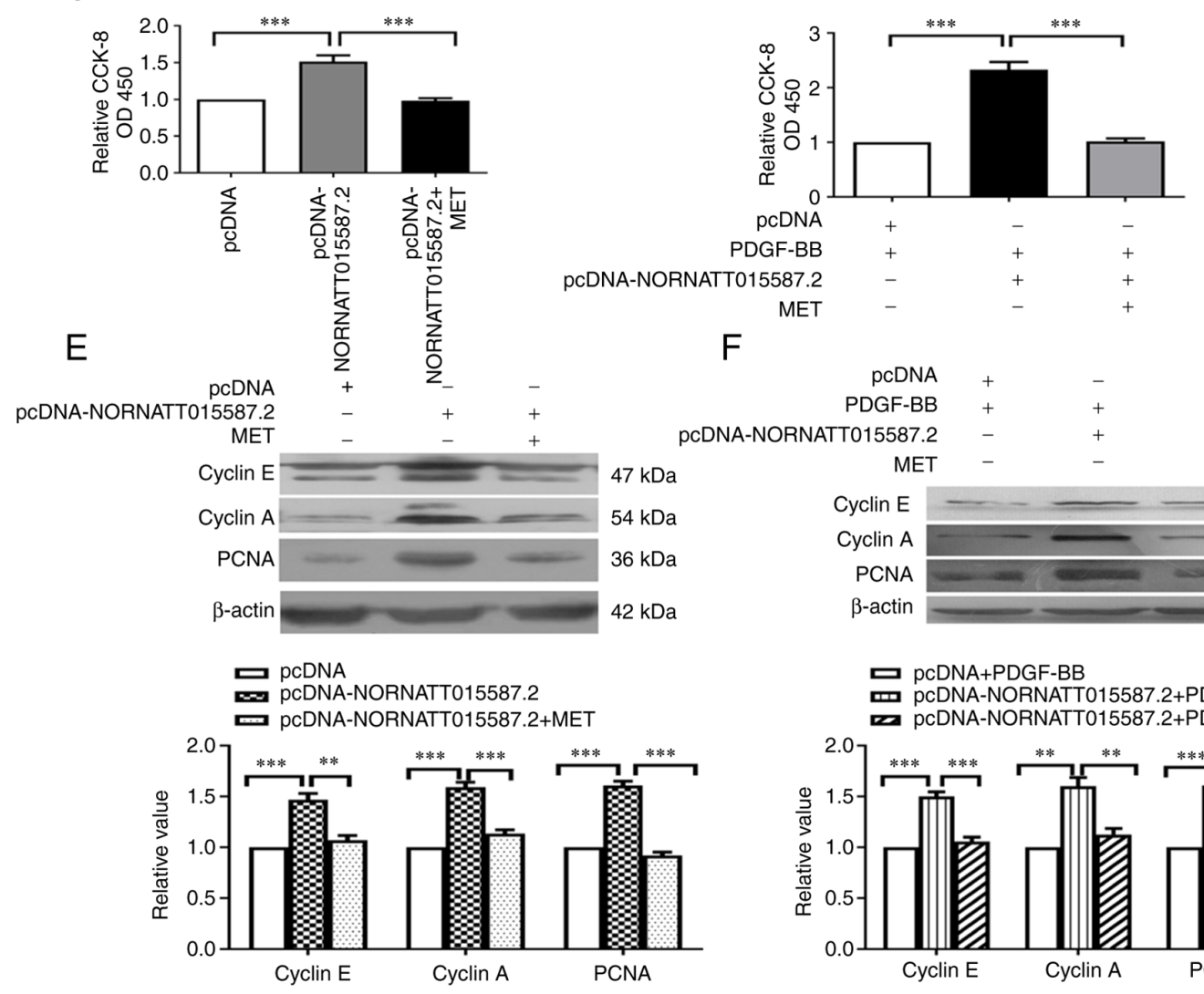

\section{$\mathrm{F}$}

$$
\text { PDGF-BB }
$$

MET
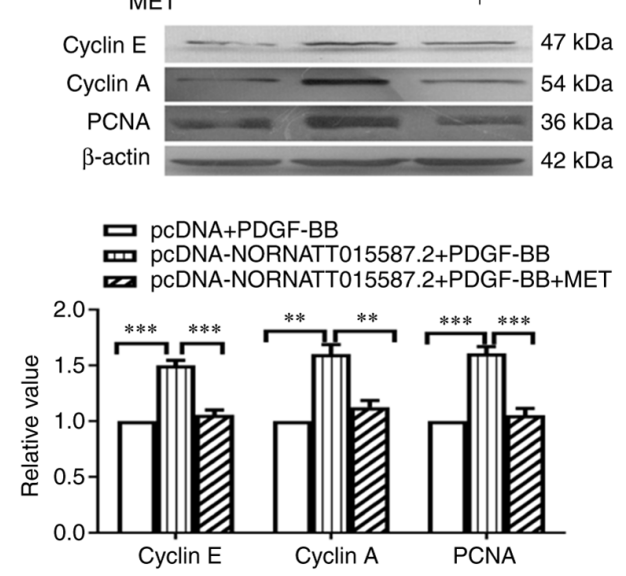

Figure 4. Effect of NONRATT015587.2 overexpression on the proliferation of PASMCs. Flow cytometry was performed to analyze the effect of NONRATT015587.2 overexpression on the proliferation of PASMCs in the (A) absence or (B) presence of the external stimulus, PDGF-BB. A CCK-8 assay was performed to analyze the proliferation of NONRATT015587.2 overexpression on the proliferation of PASMCs in the (C) absence or (D) presence of the external stimulus, PDGF-BB. Western blotting was conducted to determine the protein expression of PCNA, Cyclin A and Cyclin E after NONRATT015587.2 overexpression in the (E) absence or $(\mathrm{F})$ presence of the external stimulus, PDGF-BB. ${ }^{* *} \mathrm{P}<0.01$ and ${ }^{* * *} \mathrm{P}<0.001$ as indicated ( $\mathrm{n}=\geq 3$ ). CCK-8, Cell Counting Kit-8; MET, metformin; OD, optical density; PASMCs, pulmonary artery smooth muscle cells; PCNA, proliferating cell nuclear antigen; PDGF-BB, platelet-derived growth factor-BB.

overexpression, although MET could reverse these effects (Fig. 4C and E).

The above results indicated that endogenous NONRATT015587.2 regulated PASMC proliferation.
Therefore, the next experiment aimed to determine whether NONRATT015587.2 promoted PASMC proliferation in the presence of PDGF external stimulation. The results of flow cytometry revealed that the proportion of cell cycle $\mathrm{S}$ phase 
(DNA synthesis phase) was increased after overexpressing NONRATT015587.2 in the presence of exogenous PDGF-BB. Furthermore, MET intervention reversed the proportion of $\mathrm{S}$ phase and restored the cell cycle distribution to the level of pcDNA+PDGF-BB group (Fig. 4B). PASMCs proliferation and Cyclin E, Cyclin A, PCNA protein expression were significantly increased after overexpression of NONRATT015587.2, and MET could reverse these results in the presence of exogenous PDGF-BB (Fig. 4D and F). The results indicated that NONRATT015587.2 was a pro-proliferation factor in PASMCs, regardless of the presence or absence of PDGF-BB as an external stimulus.

Inhibitory effect of MET on PDGF-BB-stimulated PASMC proliferation is abolished by silencing $p 21$, and NONRATT015587.2 targets p21 to promote PASMC proliferation. PDGF negatively regulates p21 expression. In addition, PDGF-stimulated PASMC proliferation was inhibited by MET. The transfection efficiency of p21 silencing was verified using western blotting (Fig. 5A). The effect of p21 silencing following PDGF-BB and MET stimulation on the cell cycle progression and proliferation of PASMCs was then examined. The results suggested that p21 silencing could abolish the inhibitory effect of MET on PDGF-BB-induced PASMC proliferation. In addition, an increase in cell proliferation was observed, together with upregulation of cyclin $\mathrm{E}$, cyclin A and PCNA proteins (Fig. 5B-D). This suggested that p21 was targeted by MET to inhibit the proliferation of PASMCs and that silencing p21 could abolish the inhibitory effects of MET.

The next experiments were carried out to determine whether p21 was the regulatory target of NONRATT015587.2. NONRATT015587.2 silencing was used to test this hypothesis. The results revealed that PASMC proliferation and the protein expression of cyclin E, cyclin A and PCNA were significantly decreased following the NONRATT015587.2 knockdown (Fig. 5E and F). However, p21 silencing could rescue the inhibitory effect of NONRATT015587.2 silencing on the proliferation of PASMCs, as well as the expression of cyclin E, cyclin A and PCNA proteins to the levels of the NC group. However, after treatment with MET, the proliferation of PASMC was inhibited when NONRATT015587.2 and p21 were silenced at the same time. These results suggested that $\mathrm{p} 21$ was the target of NONRATT015587.2. Thus, MET may inhibit the proliferation of PASMCs via the NONRATT015587.2/p21 axis.

The aforementioned results suggested that endogenous NONRATT015587.2 regulated the proliferation of PASMCs by targeting $\mathrm{p} 21$. Therefore, the next experiments were designed to determine whether NONRATT015587.2 would promote PASMC proliferation in the presence of PDGF-BB external stimulation. PDGF-BB stimulated PASMC proliferation and PCNA, cyclin A and cyclin E protein expression was significantly reduced after NONRATT015587.2 silencing, and cell proliferation was inhibited. Silencing p21 reversed the effects on cell proliferation and the expression of cyclin E, cyclin A and PCNA proteins to the levels of PDGF-BB treatment alone. Following treatment with MET, the proliferation of PASMCs was reduced (Fig. 5G and $\mathrm{H}$ ). Therefore, NONRATT015587.2 may regulate the proliferation of PASMCs by targeting p21 in the presence or absence of external stimuli.

\section{Discussion}

Abnormal proliferation of PASMCs is an important feature of PAH vascular remodeling and is also the main reason for the progression of $\mathrm{PAH}$, leading to thickening of the pulmonary blood vessels, narrowing of the lumen and increased tension, which ultimately results in increased PA pressure, right heart failure and death $(3,24,40)$. Pathophysiological stimuli, such as hypoxia, inflammation and oxidative stress can promote the proliferation of PASMCs $(3,24,40)$. The proliferation of PASMCs is controlled by the cell cycle, which is in turn regulated by various signaling pathways (41). Indeed, the cell cycle is strictly regulated by cell cycle regulators, which involves a complex cascade of cellular events $(42,43)$. These regulators include cyclins, cyclin-dependent kinases (CDKs), cyclin-dependent kinase inhibitors (CKIs), retinoblastoma proteins $(\mathrm{Rb})$ and PCNA $(42,43)$. Positive regulators of the cell cycle (cyclin, CDKs, Rb and PCNA) are also known as cell cycle engines, which help cells transition through cell cycle checkpoints, thereby promoting cell proliferation and transformation (34). The activity of CDKs is controlled by cyclin regulatory subunits. These subunits bind to specific cyclins to form complexes and are regulated by CKIs at specific stages of the cell cycle. The functional activation of cyclin/CDK complexes is necessary for cell cycle progression $(27,43,44)$. PASMCs are usually in a static state in the middle PA with low-index proliferation and are in the $G_{0} / G_{1}$ phase of the cell cycle (43). Cells enter the cell cycle from a resting state, activate the cyclin/CDK complex (such as cyclin E/CDK2, cyclin A/CDK2 and cyclin D/CDK4) in the $\mathrm{G}_{1}$ phase, then trigger the transition from the $G_{0} / G_{1}$ to the $S$ phase $(42,43)$. PCNA is a gene product that is modulated by the phosphorylation of Rb. It is synthesized during the $G_{0} / G_{1}$ and $S$ phases of the cell cycle and plays an important role in the transition from the $G_{1}$ to the $S$ phase $(42,43)$. p21, a CKI, is a negative regulator of cell cycle progression $(27,28)$. p21 can bind to CDK2 or CDK4 complexes and inhibit their activity $(27,28,34)$, especially in the case of the CDK2 complex (cyclin E/CDK2, cyclin A/CDK2) (44). p21 can also interact with PCNA and play a regulatory role in S-phase DNA replication and DNA damage repair (28). Therefore, p21 inhibits cell proliferation by inhibiting $\mathrm{G}_{1} / \mathrm{S}$ cell cycle checkpoints (cyclin E/CDK2, cyclin A/CDK2 and PCNA) $(34,43)$.

The PDGF family includes four heterogeneous polypeptide chains (A-C and D), which can assemble into five different dimeric forms (PDGF-AA, PDGF-AB, PDGF-BB, PDGF-CC and PDGF-DD), among which the PDGF-BB homodimer is the strongest inducer of VSMC proliferation identified to date (1). PDGF is necessary for VSMC proliferation $(1,43)$. PDGF expression is upregulated in MCT-induced and hypoxia-induced PAH rats, as well as in the lung tissues and PASMCs of patients with PAH $(25,40,45)$. The current results also suggested that PDGF is highly expressed in pulmonary vessels of MCT induced PAH rats. PDGF-mediated VSMC proliferation is a tightly regulated process involving Ras/MAPK, PI3K/Akt, phospholipase C (PLC)- $\gamma$ and JAK/STAT signaling pathways $(1,34,42,43)$. The phosphorylation of PLC- $\gamma$, Akt, 
A
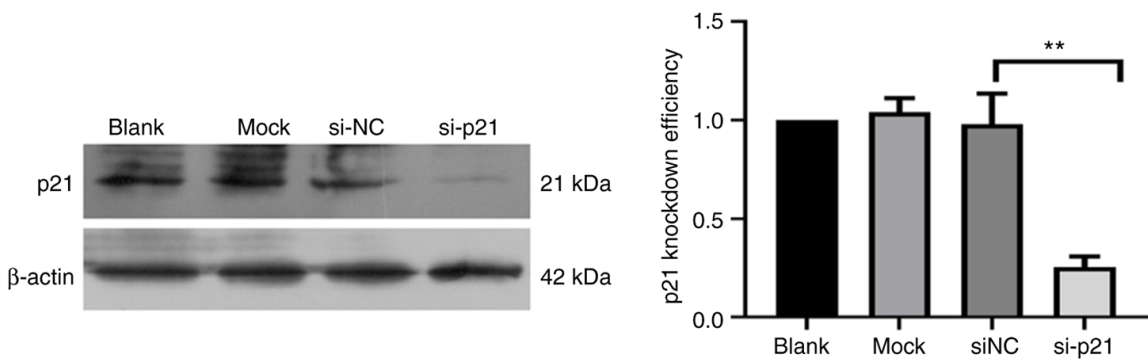

B
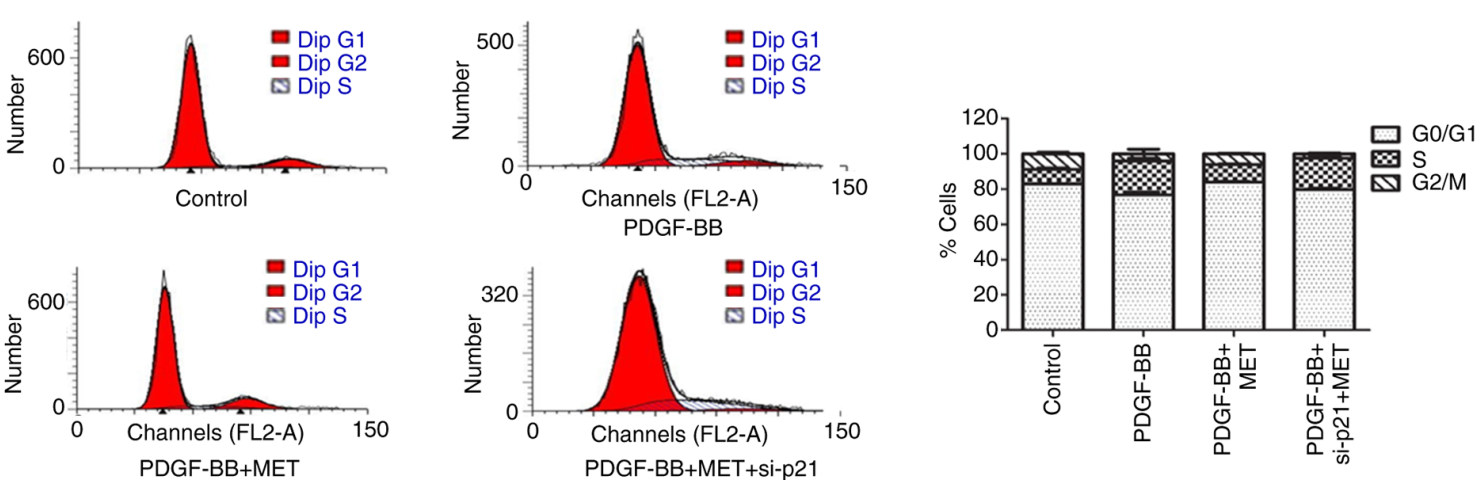

C
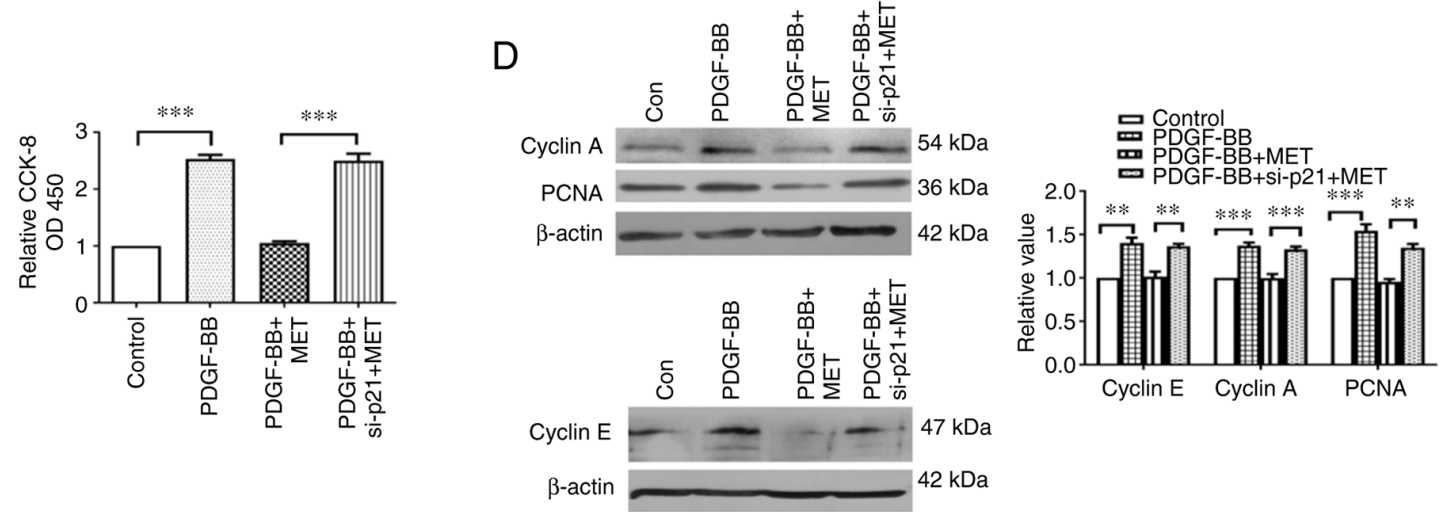

E

$\mathrm{F}$
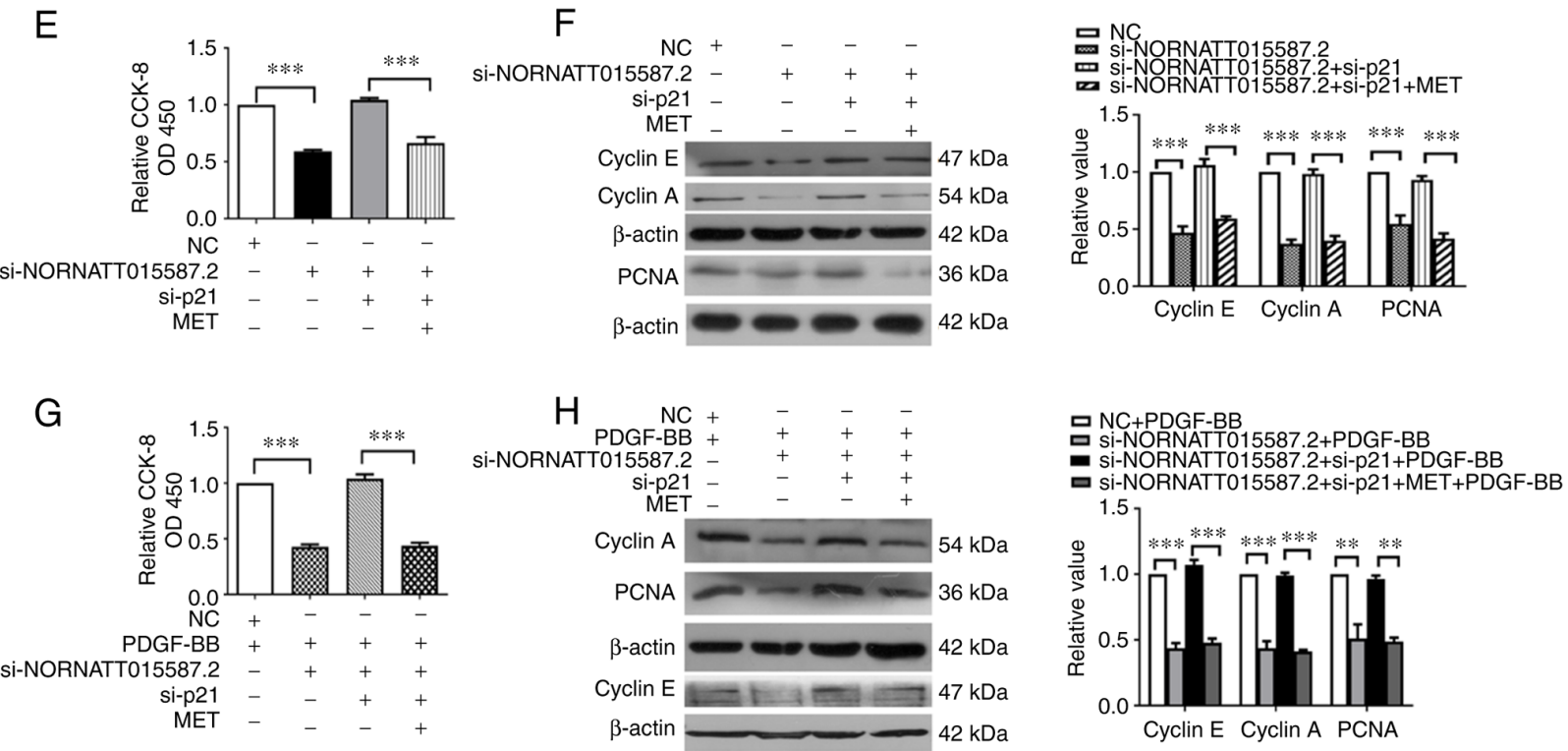

Figure 5. NONRATT015587.2 targets p21 to promote the proliferation of PASMCs, and metformin reverses this effect. (A) The efficiency of p21 silencing was assessed by western blotting. (B) Flow cytometry was performed to detect the number of cells in each phase of the cell cycle in PASMCs. (C) A CCK-8 assay was performed to determine the proliferation of PASMCs after control, PDGF-BB, PDGF-BB+MET, and PDGF-BB+si-p21+MET treatments. (E) A CCK-8 assay was performed to determine the proliferation of PASMCs after NC, si-NONRATT015587.2, si-NONRATT015587.2+si-p21 and si-NONRATT015587.2+si-p21+MET treatment. (G) A CCK-8 assay was performed to determine the proliferation of PASMCs after NC+PDGF-BB, si-NONRATT015587.2+ PDGF-BB,si-NONRATT015587.2+si-p21+PDGF-BB and si-NONRATT015587.2+si-p21+ MET+PDGF-BB treatment. $\left(\mathrm{D}, \mathrm{F}\right.$ and $\mathrm{H}$ ) The protein expression of PCNA, Cyclin A and Cyclin $\mathrm{E}$ was determined in PASMCs under different conditions. ${ }^{* * *} \mathrm{P}<0.01$ and ${ }^{* * * *} \mathrm{P}<0.001$ as indicated ( $\mathrm{n}=\geq 3$ ). CCK-8, Cell Counting Kit-8; Con, control; MET, metformin; NC, negative control; OD, optical density; PASMCs, pulmonary artery smooth muscle cells; PCNA, proliferating cell nuclear antigen; PDGF-BB, platelet-derived growth factor-BB; si, small interfering RNA. 
ERK1/2, p38 and JNK in PDGF-BB-stimulated VSMCs has been demonstrated to be significantly increased $(42,43)$. These signals represent early cues for the proliferation of VSMCs and are eventually brought together into the common regulatory pathway in the cell cycle through a complex signaling cascade $(1,42)$. PDGF promotes cell cycle transition from the $\mathrm{G}_{0} / \mathrm{G}_{1}$ phase to the $\mathrm{S}$ phase by upregulating the expression of positive cell cycle regulators (cyclin E, cyclin D, CDK2, CDK4, PCNA and S-phase kinase associated protein 2) and downregulating the expression of negative regulators (p21 and p27) to induce VSMC proliferation $(34,40,42,43)$. In the present study, PDGF-BB stimulation significantly increased the expression of cyclin E, cyclin A and PCNA protein at the $\mathrm{G}_{1} / \mathrm{S}$ cell cycle checkpoints, downregulated the expression of $\mathrm{p} 21$, accelerated the cell cycle transition from $G_{0} / G_{1}$ phase to $S$ phase and promoted cell proliferation. Previous studies, including our own, confirmed that MET could inhibit MCT-induced pulmonary vascular remodeling in PAH rats $(14,15,22)$ and PDGF-induced PASMC proliferation (34). The majority of these studies focused on MET targeting PI3K/Akt/mTOR signaling. In another study focusing on the inhibitory effect of MET on tumor cell proliferation, it was observed that MET acted as a $G_{1} / S$ cell cycle checkpoint inhibitor, which could suppress tumor cell proliferation by upregulating p21 to block the cell cycle at $\mathrm{G}_{0} / \mathrm{G}_{1}$ phase (29). To the best of our knowledge, the effect of MET on PASMC proliferation and cell cycle progression has not yet been reported. In the present study, MET could significantly inhibit the expression of $G_{1} / S$ checkpoint-related proteins (cyclin E, cyclin A and PCNA) and induce p21 expression. Cell cycle progression was blocked at the $G_{1}$ phase, thereby inhibiting the proliferation of PASMCs.

The regulation of IncRNAs in the pathogenesis of PAH has been attracting increasing attention. Several lncRNA molecules that regulate the proliferation of PASMCs have been identified, such as TCONS_00034812 (3), MEG3 (4), MALAT1 (23), Hoxaas3 (24), H19 (25) and UCA1 (26). NONRATT015587.2 is a novel lncRNA whose biological function has not yet been fully characterized. The present study confirmed that NONRATT015587.2 promoted the proliferation of PASMCs in a PAH rat model. This lncRNA was upregulated in the MCT group and downregulated in the MET + MCT group. By contrast, p21 expression was downregulated in the MCT group and upregulated in the MCT + MET group. In addition, the expression of NONRATT015587.2 was significantly upregulated in PASMCs stimulated with PDGF-BB, which was accompanied by the downregulation of p21 expression. This induced the upregulation of $G_{1} / S$ phase checkpoint-related proteins and promoted the proliferation of PASMCs. In vitro, following MET treatment, the expression of NONRATT015587.2 was downregulated, and that of p21 was upregulated, which inhibited the expression of $G_{1} / S$ checkpoint-related proteins and the proliferation of PASMCs. Thus, the expression patterns of NONRATT015587.2 and p21 and the results of MET intervention were found to be consistent between the in vivo and the in vitro experiments. In addition, our previous study demonstrated that the expression of $\mathrm{p} 21$ was negatively correlated with that of NONRATT015587.2, which is located downstream, and is jointly regulated by MCT and MET (22). In the current study, MET inhibited the expression of $\mathrm{G}_{1} / \mathrm{S}$ checkpoint-related proteins (cyclin $\mathrm{E}$, cyclin
A and PCNA), blocked the cell cycle at $\mathrm{G}_{0} / \mathrm{G}_{1}$ and inhibited PDGF-induced PASMC proliferation by upregulating p21. Silencing p21 abolished the effects of MET, upregulating the expression of $\mathrm{G}_{1} / \mathrm{S}$ phase checkpoint-related proteins, promoting the cell cycle entry into the $\mathrm{S}$ phase and restoring PASMC proliferation. This suggests that p21 is a key target for MET and that MET inhibits the proliferation of PASMCs by upregulating p21 to block the cell cycle at the $\mathrm{G}_{0} / \mathrm{G}_{1}$ phase. Furthermore, NONRATT015587.2 and p21 silencing experiments were used to verify the interaction between these two molecules. Following NONRATT015587.2 silencing, the expression of $\mathrm{G}_{1} / \mathrm{S}$ phase checkpoint-related proteins was downregulated and PASMC proliferation was inhibited. In addition, p21 silencing could rescue the inhibitory effect of NONRATT015587.2 silencing on PASMC proliferation, induce the expression of $\mathrm{G}_{1} / \mathrm{S}$ checkpoint-related proteins and promote the proliferation of PASMCs. Following treatment with MET, the expression levels of $\mathrm{G}_{1} / \mathrm{S}$-phase checkpoint-related proteins were reduced and PASMC proliferation was inhibited. These data suggest that $\mathrm{p} 21$ is the target of NONRATT015587.2. Targeting p21 to interfere with the cell cycle may represent a new research direction for PAH therapy (1). In summary, MET inhibits PASMC proliferation through NONRATT015587.2-mediated p21 upregulation, which provides insight into the pathogenesis of PAH and mechanism of action of MET.

The subcellular localization of lncRNAs is significant and is an important determinant of their functional characteristics (46). In the present study, RNA FISH analysis demonstrated that NONRATT015587.2 was located in the nucleus. Generally, lncRNAs localized in the nucleus mainly serve a role in chromatin regulatory modification and transcriptional regulation, whereas cytoplasmic lncRNAs are involved in competing endogenous RNA network regulation by adsorbing miRNAs, affecting mRNA stability and translation regulation, thus playing a regulatory role at both the transcriptional and the post-transcriptional level (23). Nuclear lncRNA molecules can bind to specific chromatin sites and act as epigenetic regulators, regulating basic cellular processes, such as proliferation or apoptosis (46). In addition, the function of lncRNAs also depends on their sequence, which determines their interaction with transcription factors and their ability to regulate target mRNA transcripts (46). Our previous study determined that p53 was involved in the regulation of the proliferation mechanism of NONRATT015587.2 (22). p53 is located in the nucleus and cytoplasm, accounting for $~ 50 \%$ separately (42). Therefore, it may be hypothesized that NONRATT015587.2 interacts with p53 in the nucleus. Activated p53 could translocate to the nucleus or shuttle between the cytoplasm and the nucleus, where it exerts its regulatory effect (4). In addition, p21 is a downstream target gene of p53 that is regulated in a p53-dependent and -independent manner $(29,30,44)$. p21 also has p53 and PCNA binding sequences, which regulate cell cycle progression and proliferation $(29,30,44)$.

The IncRNA NONRATT015587.2 has not been further verified in humans, which was a limitation to the current study. The main reason is that the conservation of lncRNA is a difficult point in current research, and its conservation is significantly lower than that of mRNA. In the absence of a corresponding genome database, its completeness and accuracy vary significantly among different laboratories. With the 
continuous in-depth study of lncRNA conservation and the continuous improvement of bioinformatics screening tools, a future constructed lncRNA reference database would be more comprehensive and accurate, and it would also have more reference value. The present study was primarily concerned with the therapeutic effect of MET on pulmonary hypertension and its mechanism. The main finding of the study was that MET reduced pulmonary vascular remodeling by regulating the expression of lncRNA. This provides a new theoretical basis for the next step in studying the therapeutic effects and pathological mechanisms of MET in patients with pulmonary hypertension. In addition, there are some newly discovered lncRNAs, such as NONRATT018084.2, NONRATT009275.2, NONRATT007865.2 and NONRATT026300.2 which require (21). Although these were not identified in our previous microarray analysis (22), further study surrounding the PA tissues of MCT and MCT+MET rats should be performed to elucidate novel regulatory mechanisms in which MET reverses pulmonary vascular remodeling. In summary, lncRNA NONRATT015587.2 could promote the expression of PASMC proliferation genes by targeting p21, while MET could upregulate p21 through NONRATT015587.2 to inhibit PDGF-BB-induced PASMC proliferation. These findings may also improve our understanding of the pathogenesis of PAH and the mechanisms underlying the action of MET.

\section{Acknowledgements}

Not applicable.

\section{Funding}

This study was supported by National Natural Science Foundation of China (grant no. 31871155), the Key Laboratory Open Project (grant no. KFKT-2103), the project of Jiangsu Provincial Commission of Health and Family Planning (grant no. QNRC2016505) and the Six Big Talent Peak C Projects (grant no. YY-110).

\section{Availability of data and materials}

The datasets used and/or analyzed during the current study are available from the corresponding author on reasonable request.

\section{Authors' contributions}

ZS and YaL contributed substantially to the conception and design of the experiments. YaL conducted all experiments and wrote the manuscript. NL conducted data analyses and modified the manuscript draft. RH and TW performed in vivo experiments. YuL was performed PCR experiments. ZS and YuL confirmed the authenticity of all the raw data. All authors read and approved the final manuscript.

\section{Ethics approval and consent to participate}

The present study was supervised and approved by the Ethics Committee of China Pharmaceutical University (approval no. 202021) and performed in accordance with the Regulations on the Administration of Laboratory Animals.

\section{Patient consent for publication}

Not applicable.

\section{Competing interests}

The authors declare that they have no competing interests.

\section{References}

1. Wang D, Uhrin P, Mocan A, Waltenberger B, Breuss JM, Tewari D, Mihaly-Bison J, Huminiecki Ł, Starzyński RR, Tzvetkov NT, et al: Vascular smooth muscle cell proliferation as a therapeutic target. Part 1: Molecular targets and pathways. Biotechnol Adv 36: 1586-1607, 2018.

2. Shimoda LA and Laurie SS: Vascular remodeling in pulmonary hypertension. J Mol Med (Berl) 91: 297-309, 2013.

3. Liu Y, Sun Z, Zhu J, Xiao B, Dong J and Li X: LncRNA-TCONS_00034812 in cell proliferation and apoptosis of pulmonary artery smooth muscle cells and its mechanism. J Cell Physiol 233: 4801-4814, 2018.

4. Sun Z, Nie X, Sun S, Dong S, Yuan C, Li Y, Xiao B, Jie D and Liu Y: Long non-coding RNA MEG3 downregulation triggers human pulmonary artery smooth muscle cell proliferation and migration via the p53 signaling pathway. Cell Physiol Biochem 42: 2569-2581, 2017.

5. Thenappan T, Ormiston ML, Ryan JJ and Archer SL: Pulmonary arterial hypertension: Pathogenesis and clinical management. BMJ 360: j5492, 2018.

6. Johnson J, Lakshmanan G, M B, R M V, Kalimuthu K and Sekar D: Computational identification of MiRNA-7110 from pulmonary arterial hypertension (PAH) ESTs: A new microRNA that links diabetes and PAH. Hypertens Res 43: 360-362, 2020.

7. Whitaker ME, Nair V, Sinari S, Dherange PA, Natarajan B, Trutter L, Brittain EL, Hemnes AR, Austin ED, Patel K, et al: Diabetes mellitus associates with increased right ventricular afterload and remodeling in pulmonary arterial hypertension. Am J Med 131: 702.e7-702.e13, 2018.

8. Hemnes AR, Luther JM, Rhodes CJ, Burgess JP, Carlson J, Fan R, Fessel JP, Fortune N, Gerszten RE, Halliday SJ, et al: Human PAH is characterized by a pattern of lipid-related insulin resistance. JCI Insight 4: e123611, 2019.

9. Zhou T, Xu X, Du M, Zhao T and Wang J: A preclinical overview of metformin for the treatment of type 2 diabetes. Biomed Pharmacother 106: 1227-1235, 2018.

10. Li M, Li X, Zhang H and Lu Y: Molecular mechanisms of metformin for diabetes and cancer treatment. Front Physiol 9: 1039, 2018.

11. Zi F, Zi H, Li Y, He J, Shi Q and Cai Z: Metformin and cancer: An existing drug for cancer prevention and therapy. Oncol Lett 15: 683-690, 2018.

12. Ikhlas $\mathbf{S}$ and Ahmad M: Metformin: Insights into its anticancer potential with special reference to AMPK dependent and independent pathways. Life Sci 185: 53-62, 2017.

13. Agard C, Rolli-Derkinderen M, Dumas-de-La-Roque E, Rio M, Sagan C, Savineau JP, Loirand G and Pacaud P: Protective role of the antidiabetic drug metformin against chronic experimental pulmonary hypertension. Br J Pharmacol 158: 1285-1294, 2009.

14. Li S, Han D, Zhang Y, Xie X, Ke R, Zhu Y, Liu L, Song Y, Yang L and Li M: Activation of AMPK prevents monocrotaline-induced extracellular matrix remodeling of pulmonary artery. Med Sci Monit Basic Res 22: 27-33, 2016.

15. Zhai C, Shi W, Feng W, Zhu Y, Wang J, Li S, Yan X, Wang Q, Zhang Q, Chai L, et al: Activation of AMPK prevents monocrotaline-induced pulmonary arterial hypertension by suppression of NF- $\mathrm{B}$-mediated autophagy activation. Life Sci 208: 87-95, 2018.

16. Chaumeil J, Le Baccon P, Wutz A and Heard E: A novel role for Xist RNA in the formation of a repressive nuclear compartment into which genes are recruited when silenced. Genes Dev 20: 2223-2237, 2006.

17. Gutschner T and Diederichs S: The hallmarks of cancer: A long non-coding RNA point of view. RNA Biol 9: 703-719, 2012.

18. Ling H, Vincent K, Pichler M, Fodde R, Berindan-Neagoe I, Slack FJ and Calin GA: Junk DNA and the long non-coding RNA twist in cancer genetics. Oncogene 34: 5003-5011, 2015. 
19. Greco S, Gorospe $M$ and Martelli F: Noncoding RNA in age-related cardiovascular diseases. J Mol Cell Cardiol 83: 142-155, 2015.

20. Vencken SF, Greene CM and McKiernan PJ: Non-coding RNA as lung disease biomarkers. Thorax 70: 501-503, 2015.

21. Hou S, Chen D, Liu J, Chen S, Zhang X, Zhang Y, Li M, Pan W, Zhou D, Guan L and Ge J: Profiling and molecular mechanism analysis of long non-coding RNAs and mRNAs in pulmonary arterial hypertension rat models. Front Pharmacol 12: 709816, 2021.

22. Sun Z, Liu Y, Yu F, Xu Y, Yanli L and Liu N: Long non-coding RNA and mRNA profile analysis of metformin to reverse the pulmonary hypertension vascular remodeling induced by monocrotaline. Biomed Pharmacother 115: 108933, 2019.

23. Brock M, Schuoler C, Leuenberger C, Bühlmann C, Haider TJ, Vogel J, Ulrich S, Gassmann M, Kohler M and Huber LC: Analysis of hypoxia-induced noncoding RNAs reveals metastasis-associated lung adenocarcinoma transcript 1 as an important regulator of vascular smooth muscle cell proliferation. Exp Biol Med (Maywood) 242: 487-496, 2017.

24. Zhang H, Liu Y, Yan L, Wang S, Zhang M, Ma C, Zheng X, Chen $\mathrm{H}$ and Zhu D: Long noncoding RNA Hoxaas 3 contributes to hypoxia-induced pulmonary artery smooth muscle cell proliferation. Cardiovasc Res 115: 647-657, 2019.

25. Su H, Xu X, Yan C, Shi Y, Hu Y, Dong L, Ying S, Ying K and Zhang R: LncRNA H19 promotes the proliferation of pulmonary artery smooth muscle cells through $\mathrm{AT}_{1} \mathrm{R}$ via sponging let-7b in monocrotaline-induced pulmonary arterial hypertension. Respir Res 19: 254, 2018

26. Zhu TT, Sun RL, Yin YL, Quan JP, Song P, Xu J, Zhang MX and Li P: Long noncoding RNA UCA1 promotes the proliferation of hypoxic human pulmonary artery smooth muscle cells. Pflugers Arch 471: 347-355, 2019.

27. Zhang Y, Wang Y, Wang X, Zhang Y, Eisner GM, Asico LD, Jose PA and Zeng C: Insulin promotes vascular smooth muscle cell proliferation via microRNA-208-mediated downregulation of p21. J Hypertens 29: 1560-1568, 2011.

28. Bi M, Yu H, Huang B and Tang C: Long non-coding RNA PCAT-1 over-expression promotes proliferation and metastasis in gastric cancer cells through regulating CDKN1A. Gene 626 : 337-343, 2017

29. Takahashi A, Kimura F, Yamanaka A, Takebayashi A, Kita N, Takahashi K and Murakami T: Metformin impairs growth of endometrial cancer cells via cell cycle arrest and concomitant autophagy and apoptosis. Cancer Cell Int 14: 53, 2014.

30. FornariF,MilazzoM,ChiecoP,NegriniM,MarascoE,CapranicoG, Mantovani V, Marinello J, Sabbioni S, Callegari E, et al: In hepatocellular carcinoma miR-519d is up-regulated by $\mathrm{p} 53$ and DNA hypomethylation and targets CDKN1A/p21, PTEN, AKT3 and TIMP2. J Pathol 227: 275-285, 2012.

31. Dean A, Nilsen M, Loughlin L, Salt IP and MacLean MR: Metformin reverses development of pulmonary hypertension via aromatase inhibition. Hypertension 68: 446-454, 2016.

32. Livak KJ and Schmittgen TD: Analysis of relative gene expression data using real-time quantitative PCR and the 2(-Delta Delta C(T)) method. Methods 25: 402-408, 2001

33. Xu X, Gu J, Ding X, Ge G, Zang X, Ji R, Shao M, Mao Z, Zhang Y, Zhang J, et al: LINC00978 promotes the progression of hepatocellular carcinoma by regulating EZH2-mediated silencing of p21 and E-cadherin expression. Cell Death Dis 10: 752, 2019.
34. Song Y, Wu Y, Su X, Zhu Y, Liu L, Pan Y, Zhu B, Yang L, Gao L and Li M: Activation of AMPK inhibits PDGF-induced pulmonary arterial smooth muscle cells proliferation and its potential mechanisms. Pharmacol Res 107: 117-124, 2016

35. Elgendy M, Cirò M, Hosseini A, Weiszmann J, Mazzarella L, Ferrari E, Cazzoli R, Curigliano G, DeCensi A, Bonanni B, et al: Combination of hypoglycemia and metformin impairs tumor metabolic plasticity and growth by modulating the PP2A-GSK33-MCL-1 axis. Cancer Cell 35: 798-815.e5, 2019.

36. Li B, Zhou P, Xu K, Chen T, Jiao J, Wei H, Yang X, Xu W, Wan W and Xiao J: Metformin induces cell cycle arrest, apoptosis and autophagy through ROS/JNK signaling pathway in human osteosarcoma. Int J Biol Sci 16: 74-84, 2020.

37. Xia C, Liu C, He Z, Cai Y and Chen J: Metformin inhibits cervical cancer cell proliferation by modulating PI3K/Akt-induced major histocompatibility complex class I-related chain A gene expression. J Exp Clin Cancer Res 39: 127, 2020.

38. Zahra MH, Afify SM, Hassan G, Nawara HM, Kumon K, Seno A and Seno M: Metformin suppresses self-renewal and stemness of cancer stem cell models derived from pluripotent stem cells. Cell Biochem Funct 39: 896-907, 2021.

39. Liu Y, Xu Y, Zhu J, Li H, Zhang J, Yang G and Sun Z: Metformin prevents progression of experimental pulmonary hypertension via inhibition of autophagy and activation of adenosine monophosphate-activated protein kinase. J Vasc Res 56: 117-128, 2019.

40. Zhuang W, Lian G, Huang B, Du A, Gong J, Xiao G, Xu C, Wang H and Xie L: CPT1 regulates the proliferation of pulmonary artery smooth muscle cells through the AMPK-p53-p21 pathway in pulmonary arterial hypertension. Mol Cell Biochem 455: $169-183,2019$.

41. Lee J and Kang H: Hypoxia promotes vascular smooth muscle cell proliferation through microRNA-mediated suppression of cyclin-dependent kinase inhibitors. Cells 8: 802, 2019.

42. Kwon H, Lee JJ, Lee JH, Cho WK, Gu MJ, Lee KJ and Ma JY Cinnamon and its components suppress vascular smooth muscle cell proliferation by up-regulating cyclin-dependent kinase inhibitors. Am J Chin Med 43: 621-636, 2015.

43. Yu JY, Lee JJ, Jung JK, Kim TJ, Yoo HS, Yun YP and Lee JC: JY0691, a newly synthesized obovatol derivative, inhibits cell cycle progression of rat aortic smooth muscle cells through up-regulation of p21(cip1). Eur J Pharmacol 624: 23-30, 2009.

44. Poon RY, Jiang W, Toyoshima H and Hunter T: Cyclin-dependent kinases are inactivated by a combination of p21 and Thr-14/Tyr-15 phosphorylation after UV-induced DNA damage. J Biol Chem 271: 13283-13291, 1996.

45. Perros F, Montani D, Dorfmüller P, Durand-Gasselin I, Tcherakian C, Le Pavec J, Mazmanian M, Fadel E, Mussot S, Mercier O, et al: Platelet-derived growth factor expression and function in idiopathic pulmonary arterial hypertension. Am J Respir Crit Care Med 178: 81-88, 2008.

46. Jandl K, Thekkekara Puthenparampil H, Marsh LM, Hoffmann J, Wilhelm J, Veith C, Sinn K, Klepetko W, Olschewski H, Olschewski A, et al: Long non-coding RNAs influence the transcriptome in pulmonary arterial hypertension: The role of PAXIP1-AS1. J Pathol 247: 357-370, 2019.

This work is licensed under a Creative Commons Attribution-NonCommercial-NoDerivatives 4.0 International (CC BY-NC-ND 4.0) License. 